\title{
Critical Study
}

\section{Walton's Informal Logic: A Handbook for Critical Argumentation}

\author{
JAMES B. FREEMAN Hunter College-CUNY
}

Douglas N. Walton: Informal Logic: A Handbook for Critical Argumentation. Cambridge: Cambridge University Press, 1989. xiii, $292 \mathrm{pp}$. US \$44.50 ISBN 0-521-37032-9 cloth, \$12.95 ISBN 0-521-37925-3 paper.

Douglas Walton announces that the purpose of Informal Logic "is to furnish the reader with the basic methods of critical analysis of arguments as they occur in natural language in the real marketplace of persuasion on controversial issues in politics, law, science, and all aspects of daily life," "to help the reader use critical methods to evaluate impartially and reasonably the strengths and weaknesses of arguments."2 To accomplish this purpose, Walton first discusses the theory of dialogue, identifying types of dialogue and what makes dialogue reasoned, reasonable, or critical. With this as background, he then turns to surveying a large number of argument types or argumentation schemes, as he might prefer to call them. He covers a lot of very familiar ground here, because instances of many of these schemes are also instances of well-discussed fallacies. Walton's discussion includes consideration of complex questions, arguments from ignorance, begging the question, problems of irrelevance, appeals to popularity, force, and pity, the ad hominem appeals, appeals to authoritywhen legitimate and when not, problems with statistics, post hoc causal arguments, ambiguity, vagueness, equivocation, arguments from analogy, slippery slope. There is also a chapter on deductive logic, including a discussion of inconsistency and the fallacies of composition and division.

Walton's characterization of fallacies is quite standard from the perspective of anyone familiar with the informal logic textbook literature. What makes his approach original is his attempt to relate these characterizations to the theory of dialogue, to explicate what makes certain fallacies fallacious in terms of violating rules of reasoned dialogue, and to identify non-fallacious instances of many of these types of argument. In connection with this project, Walton offers in Chapters Six, Seven, and Eight rosters of critical questions which might be asked in dialogue to challenge a proponent's contention. There is much good material here, especially the questions in Chapter Seven on evaluating appeals to authority and in Chapter Eight on induction. Here his exposition of the critical questions one can ask in connection with statistical claims and causal arguments provides a substantial way to critically assess these claims and arguments.

One feature of Walton's understanding of argument appraisal strikes us as especially commendable. "Fallacy," as Walton recognizes, has very strong connotations. To label an argument a fallacy is to suggest that its flaws are beyond remediation. It is not just that there is some gap in the argument, that the arguer has left out some information which he should have supplied and could supply perhaps under prompting. A fallacious argument is so bad that it cannot be fixed. But this means, as Walton 
points out, that there are more ways to criticize an argument than labelling it fallacious.

\begin{abstract}
There is much to be said about arguments that are neither perfectly bad (fallacious) nor perfectly good. In arguments on controversial subjects, the job of the reasonable critic is not necessarily to show that an argument he criticizes is fallacious, logically inconsistent, or based on worthless evidence that can be rejected completely. Most often, such strong refutation is simply not appropriate. More often, the job of the critic is to show that an argument is open to reasonable doubt or lacks needed support and is therefore open to questioning...to reasonable criticism. That, in itself, may be a very valuable job, and the critic may have no more to do to have achieved a worthwhile objective. By shifting the burden of proof, a criticism may be enough to make an audience withdraw its commitment to an argument. ${ }^{3}$
\end{abstract}

Walton should be further commended for clarifying, right at the beginning of his discussion of emotional appeals, that an appeal to emotion per se is no fallacy, and that many times, as in issues of morals and values, our instincts for what is right and our convictions, even those passionately held, may give us "some of the best reasons for adopting a certain position. "4t is only when our emotions lead us to accept weaker arguments when stronger ones are available, or to omit asking critical questions before accepting an argument, that they become problematic.

Although I find Walton's essay to have these positive features, my overall evaluation is not positive. My critical reactions can be summed up in one word-."unfocused." I find a lack of focus throughout this book, manifested in various ways and at various levels. I find a lack of focus in Walton's discussion of dialogue-the very theoretical core of the book, in the directions he gives for carrying out logical critique, and at many points in his evaluation of particular arguments. I even find a lack of focus in the intended audience for the book. It is clearly not a textbook, for it includes no exercises. It is not addressed to the lower division college student. Nor is it a treatise for scholars in informal logic and argumentation. Its coverage of traditional informal fallacies and related argument patterns, which comprises a good portion of its content, seems intended to present these concepts to the reader for the first time. Most likely, Walton has already indicated the audience by incorporating "handbook" into the subtitle. This is a book intended for the general educated reader interested in reasoned argument. But if so, there are some anomalies, which appear right at the very first paragraph of the Preface. Walton here uses such terms as "argumentation scheme," "pragmatic skills," and "type of challenge." "These are technical terms needing explication for the general educated audience, and they are not the only technical terms appearing in the Preface. But this is minor compared to the three problems identified above. I want to develop specifically how I find a lack of focus in Walton's basic theoretical conception and in directions for applying logical critique. To dwell on all the instances of lack of focus in Walton's discussion of particular arguments or fallacies would be tedious. But I shall discuss those I find to be particularly striking or egregious.

Before saying anything in criticism of Walton, however, I want to state explicitly my conception of logic and logical criticism. The reader should know "where I am coming from." I take the very standard view that logic is the appraisal of reasoning or argument. More specifically, logic is concerned with whether the premises of an argument give us good reason, and how good or strong a reason, for accepting its conclusion. Hence, doing logic involves asking such critical questions as

What is the structure of the argument? What does that expression mean? Why should we accept the premises?

Are the premises relevant to the conclusion?

How strongly do the premises support the conclusion-is this support adequate?

These questions epitomize much of the work 
of logical analysis and evaluation, especially as it is carried out in informal logic. Indeed, the last three questions are classic. They constitute the agenda Johnson and Blair introduced for logical evaluation in Logical Self-Defense [1977] with their basic fallacies of irrelevant reason, hasty conclusion, and problematic premise. ${ }^{6}$ Hence anyone proposing a tool, technique, consideration, or rationale for logical appraisal should either be sure that it is obviously connected to answering these basic questions or should demonstrate how it is connected. (This assumes, of course, that he accepts the appropriateness of these questions as characterizing logical critique. If not, he should argue specifically against this conception of logic and for his alternative view.) If we say that an argument is logically deficient because it instances some feature $F$, we must be clear why $F$ is connected to the considerations contained in our basic questions.

There is a presupposition in this conception of logical criticism which I should mention at this point. Its significance will appear shortly. The presupposition is that logical appraisal applies to arguments as texts. This is not to say that the texts need to be written rather than spoken. But it does mean that logical appraisal takes an argument as a text, a structured linguistic entity about which we can ask our critical questions.

Having stated our background position on the nature of the logical enterprise, a position which will color our criticisms of Walton, let us proceed to examine how we find Walton's discussion unfocused in each of the three main areas mentionedbasic theory, directions for application, and discussion of specific issues. The basic, core theory behind Walton's approach to logical evaluation is the theory of dialogue. We turn first to Walton's use of that theory.

\section{Walton on dialogues}

One of Walton's fundamental contentions is that arguments occur in the context of dialogues and must be evaluated with reference to their dialogue context. Walton begins by defining a dialogue as "a sequence of exchanges of messages or speech acts [typically of questions and replies] between two (or more) participants." $7 \mathrm{He}$ adds that every dialogue has a goal, which fosters an obligation for each participant "to work toward fulfilling his own goal....and... to cooperate with the other participant's fulfillment of his goal." ${ }^{8}$ Walton then makes this significant statement, which we shall label BPE for basic principle of evaluation:

BPE The basic reason that any argument can be criticized as a bad argument always comes down to a failure to meet one of these basic obligations. ${ }^{9}$

If this is a criterion for logical evaluation, it is distinctly problematic. The problem is that "goal" is ambiguous. We might expect that in one sense each dialogue has as its goal some issue to be resolved or question to be answered, e.g.

RESOLVED: Abortions should be permitted only in cases of rape, incest, or serious danger to the mother's life or health.

The goal of each participant is determined by whether he takes the affirmative or negative side of this issue. But a participant could have other items on his agenda which might also legitimately be called "goals." In a personal quarrel type of dialogue, the goal is to hit the "opponent at all costs, using any means, whether reasonable, fair, or not." 10 In a debate, the goal is to win by properly impressing the judges. Walton points out that in the quarrel, logically cogent argument is by and large discarded, and the debate permits and may even prize logically fallacious argument. The problem is that in the light of BPE, it is not clear why these are faults. If my goal is to hit my opponent as hard as I can-verbally not physically - then why shouldn't my use of ad hominem and other fallacious emotional appeals be perfectly correct according to BPE? Doesn't it satisfy my obligation to 
work towards fulfilling my goal? Similarly in a debate, couldn't a fallacious argument be impressively clever and so score big with the judges? Wouldn't that advance my goal? Perhaps Walton would reply that although these moves might clearly satisfy one participant's obligation to fulfill his own goal, they would interfere with his obligation to co-operate with the other participant. That would bring it under BPE censure. But is this true? At least in some situations, couldn't my attacking the opponent cause me to drop my guard and expose me to counterattack? Wouldn't I be co-operating nicely with my opponent in helping him to achieve his goal? On the other hand, suppose I present facts which cogently support my side of the issue and ask critical questions of my opponent, exposing the weaknesses of his side. How then am I co-operating with my opponent? It would seem that these moves are the hallmark of reasoned dialogue, yet why are they not censured by BPE?

The ambiguity of "goal" makes the connection between the logical criteria of cogent argument and the pragmatic criterion expressed in BPE totally obscure. If the goal of dialogue is to critically debate some issue, reaching that goal should presuppose logically cogent argument. Notice that each participant in a dialogue could share that goal. But if each participant has his own goal, determined at least in part by his own agenda, it is not at all clear how or why logically cogent argument is required.

Perhaps Walton did not intend BPE to be a normative criterion for the logical cogency of arguments occurring in any sort of dialogue, but only for those in particular types of dialogue. Should there be an intrinsic connection between the constituting features of a particular type of dialogue and logical cogency, then BPE might be an acceptable criterion for arguments arising in those dialogues. Walton identifies the persuasion dialogue or critical discussion as the most important for critical argumentation. In a critical discussion, each of two par. ticipants seeks "to prove his own thesis by the rules of inference from the concessions of the other participant." "I A participant then incurs both the obligation to construct a proof of his own thesis (Walton later clarifies that this does not mean a deductively valid argument) and to reveal his own commitments to the other participant. A critical discussion provides a "model of good dialogue because it has normative rules that, taken together, set a standard of how good persuasion dialogue should take place." 12

There is already a problem here, however, because there is no requirement that each participant's concessions be rationally warranted. Unlike a fourth type of dialogue, inquiry, where the premises are known to be true, in a critical discussion each participant may simply argue from the other's concessions and each participant "is free to concede any proposition he cares to. " 13 But surely in logical or rational argument, we should want the premises either to be true or to be the most plausible, best candidates for the truth that we can identify. Otherwise we can criticize the argument on grounds of problematic premise. We should think it a distinct fault in an argument if some significant objection to a premise, such as the higher plausibility of some alternative, went unanswered. But this is apparently not mirrored in the critical discussion model.

What actually is mirrored seems unclear. At one point, Walton says "The positive rules of persuasion dialogue provide a normative model of good persuasion dialogue." 14 But I find no enumeration or exposition of just what these rules are. Walton does, however, enumerate some of the negative rules:

\section{NEGATIVE RULES OF PERSUASION DIALOGUE}

\section{Opening stage}

1. Unlicensed shifts from one type of dialogue to another are not allowed.

\section{Confrontation stage}

1. Unlicensed attempts to change the agenda are not allowed.

2. Refusal to agree to a specific agenda of 
dialogue prohibits continuing to the argumentation stage.

\section{Argumentation stage}

1. Not making a serious effort to fulfill an obligation is bad strategy. Notable here are failures to meet a burden of proof or to defend a commitment when challenged.

2. Trying to shift your burden of proof to the other party, or otherwise alter the burden of proof illicitly, is not allowed.

3. Purporting to carry out an internal proof by using premises that have not been conceded by the other party is not allowed.

4. Appealing to external sources of proof without backing up your argument properly can be subject to objection.

5 . Failures of relevance can include providing the wrong thesis, wandering away from the point to be proved, or answering the wrong question in a dialogue.

6. Failing to ask questions that are appropriate for a given stage of dialogue should be prohibited, along with asking questions that are inappropriate.

7. Failing to reply appropriately to questions should not be allowed, including replies that are unduly evasive.

8. Failing to define, clarify, or justify the meaning or definition of a significant term used in an argument, in accord with standards of precision appropriate to the discussion, is a violation, if the use of this term is challenged by another participant.

\section{Closing stage}

1. A participant must not try to force the premature closure of a dialogue until it is properly closed, either by mutual agreement or by fulfillment of the goal of the dialogue. ${ }^{15}$

Now it is clear that for some of these rules, most notably (5) and (8) for the argumentation stage, there is an obvious connection to the criteria for logically cogent argument that we have presented. Failures of relevance and failure to clarify meaning when necessary violate standards of logical cogency. Walton claims, "In general..., for every fallacy or blunder in a context of dialogue, there is some rule for the conduct of the discussion that has been broken or tampered with." 16 This is a very interesting remark. But we may ask whether the violation of the rule explains why a fallacy or blunder is a fallacy or blunder, a logical error or deficiency. Why, for example, in a move which is an unlicensed attempt to change the agenda, or an unlicensed attempt to shift from one type of dialogue to another, do we have a logical error? What is logically wrong with a premature closing of dialogue? Why would that adversely affect the logical cogency of an argument embodied in that dialogue?

What is the connection between these pragmatic dialogue rules and logical cogency? It is Walton's intent to develop this throughout his essay. It seems unfortunate that he simply lists these rules without developing them to some extent. Without development, it is not clear just exactly what is being censured. If these rules are to provide a touchstone for evaluating argument, they should be explicated to some degree. At least, there should be indications on how each rule is developed in some later section of the book, but Walton does not provide even this. He does indicate how some fallacies are connected to violating rules, but there does not seem to be any attempt to systematically connect the rules to the fallacies. Indeed, in his examination of certain informal fallacies, Walton makes no reference to the rules at all.

Hence, Walton does not explicate the connection, essential from my perspective, between his dialogue rules and the criteria of logical evaluation. Although, intuitively, satisfying these rules would seem to be conditions of rational or reasoned dialogue, for a handbook on logic we need to be clear on how violating the rules constitutes a logical deficiency. Walton has not focused on this issue, and this leaves his presentation of the basic theoretical core of his approach unfocused, at least from my perspective. As we pointed out at the beginning 
of this section, Walton turns to considering dialogue theory because he believes arguments occur in the context of dialogues and must be evaluated with reference to the dialogues in which they occur. This raises issues for the application of the method Walton suggests. We turn to these issues in the next section.

\section{Walton on evaluating arguments}

When we do logical analysis and evaluation, what sort of thing gets analyzed and evaluated? As we claimed above, it is an argumentative text, a structured linguistic entity. Although the argument may have developed through some dialogical process, when expressed as a text it takes on a life of its own. In particular, it can be transmitted to others either through written essay or spoken address without making much, if any, indication of the dialogue in which it developed. What would it mean then to evaluate such an argument in the context of dialogue? Yet in the Preface Walton says, "A basic requirement of critical argumentation is that any argument that a critic attempts to evaluate must be set out and sympathetically appreciated in the context of dialogue in which the argument occurs." 17 How then are we to evaluate an argument text which does not obviously occur in a dialogue?

Walton suggests "This means that we must sometimes contend with lengthy and complex arguments, and we must sometimes probe in depth the unstated parts of argument, the arguer's position and commitments as indicated by the evidence of the text, and the question that the argument was supposed to answer." 18 Without doubt, all these considerations are proper and apposite in evaluating an argumentative text, especially a "real life" argumentative text. But we are still, by and large, doing textual analysis rather than dialogue analysis. We are not identifying a dialogue context of an argument the way we might identify the textual context of an argument which occurs, for example, within a larger paragraph or passage. We are imaginatively reconstructing the dialogue context, not inspecting the context of the argument as presented. I find it disconcerting to speak as if every argument occurs in the context of dialogue. That suggests to me that given an argument, we can readily identify the dialogue in which it occurs, as we can readily identify the textual context, when both argument and context are furnished. Perhaps I am belaboring this point. Perhaps Walton has indicated that this is not his view when he unpacks what it means to see an argument in dialogical context-contend with lengthy and complex arguments, probe unwarranted assumptions and commitments.

But notice that Walton here is bidding us to do textual analysis, rather than analysis of argument in two-party dialogues. Speaking of this textual analysis as seeing an argument in the context of dialogue blurs, to my mind, a well known and important distinction, that between argument as process and argument as product. We may regard the process in which one or more persons attempt to persuade others to accept some claim as argument. This is dialogical. It involves at least potential interaction. But when the reasoning is abstracted from this dialogue context and "laid out" in the form of a structured text, we have an argument as product. Not only does slipping from talk of dialogue to talk of text blur the process/ product distinction, as Joseph W. Wenzel points out in "Jürgen Habermas and the Dialectical Perspective on Argumentation" [1979], process and product indicate different perspectives on argument, adopted by different disciplines in approaching the phenomenon of argumentation, with different criteria of evaluation. Rhetoric takes the perspective of argument as process, "the phenomena of one or more social actors addressing symbolic appeals to others in an effort to win adherence to theses... The central concern of rhetoric is to determine what constitutes effectiveness in arguing." 19 Logic takes the perspective of argument as 
product, treating texts as structured and determining the soundness of arguments. ${ }^{20}$ Effectiveness deals with the persuasive force of arguments, soundness with their logically convincing character. ${ }^{21}$ Clearly, it would seem the height of confusion to apply tools and standards for one investigation to the problems of another.

We must mention, in this connection, that Wenzel identifies a third, less familiar perspective on argumentation, but one which is highly congruent with Walton's project. This perspective views argument as procedure and is adopted by dialectic. Argument as procedure is "a systematic management of discourse for the purpose of achieving critical decisions." ${ }_{22}$ Here argument is more than just a process. It is process subject to governance by overtly accepted rules of procedure, enabling the interlocutors "to reach joint understanding or critical decision." ${ }^{23}$ We might very fairly view persuasion dialogues or critical discussions as procedures and Walton's rules as specifying how those procedures should be carried out. That dialectical analysis and evaluation should have a bearing on logical analysis and evaluation and illuminate logical issues, especially as treated in informal logic, seems a very fruitful hypothesis. But it is one which must be developed and defended. It will not do to slip from one to the other or to speak as if dialectical critique and logical critique are the same thing. That puts the whole application of one's critical tools out of focus.

Having examined how there are problems of focus in both Walton's exposition of dialogue theory and his views on application to logical practice, we now want to examine Walton's treatment of specific problems and issues and how problems of focus arise here.

\section{Walton on particular issues}

1. Loaded questions and reasonable dialogue. What is wrong with such questions as

Have you stopped beating your spouse?
Walton identifies the difficulty quite neatly. Such questions demand "yes" or "no" as a direct answer. Answering either way, the respondent would be committed to the proposition that he was a spouse beater. That is a presupposition of the question in that it is "a proposition that is presumed to be acceptable to the respondent when the question is asked, so that the respondent becomes committed to the proposition when he gives any direct answer." 24 Anyone who answers a question directly "automatically becomes committed to all its presuppositions." ${ }^{25}$ But presumably the respondent is not committed to that proposition or does not want to admit it as a commitment. It is an unwelcome commitment and the question is loaded. ${ }^{26}$

What is wrong with loaded questions? Certainly it might be wrong, from an ethical point of view, to trick or coerce someone into making commitments he or she does not want to make. But what is wrong from a logical point of view, from the perspective of evaluating arguments? True, someone may not want to make these commitments. But why should that indicate a logical error? Or why should the fact that the commitment was forced be a logical error? Yet this seems to be precisely how Walton understands loaded questions and their problematic nature.
Whether a question is loaded depends on the position of the answerer. If the answerer clearly would not want to be committed to a presupposition of a particular question, then the question may be described as load- ed with respect to his position. ${ }^{27}$

But why should the answerer's wants or desires count here? If the answerer does not want to admit the presupposition because it falsely describes him, that is one thing. But then it would seem that the question is objectionable because its presupposition is false. But an answerer might not want to be committed to a presupposition because it would damage the case for his thesis or because he wanted to hide the truth about something. But, especially if the presupposition were true or well warranted, why 
should the question be problematic in such a case? From my perspective, Walton has not focussed on a logical issue here.

Walton continues his analysis by saying

The underlying problem with the spousebeating question... is that it does not fit into a reasonable order of questioning and answering in the context of dialogue... The spouse-beating question, to be a reasonable question, presupposes that the respondent has already given or is committed to affirmative answers to two prior questions asked in the following order: (1) Do you have a spouse?

(2) Have you ever beaten your spouse? ${ }^{28}$

This may be all right, as far as it goes, but I would like to ask "What are the principles behind this order? How did Walton generate these two questions?" Although that these two questions should have been answered in this order may seem intuitive, will this be so in every case? The reader needs to be able to generate these questions for himself, if he is to have a general tool for evaluating loaded questions. To do this, we need some general principles. A handbook should supply them.

These problems pervade Walton's discussion of reasonable dialogue, which follows his discussion of the spouse beating question. He makes reference to there being a reasonable order of dialogue. But I nowhere see this order spelled out. True, we can intuitively see that before asking "Are you a pacifist or a warmonger?' 29 one should settle whether the respondent can be just one or the other and not some third alternative. The problem is that Walton here has left all this at the intuitive level. He has not focused on spelling out a general procedure.

2. Arguments ad ignorantiam. Walton defines an ad ignorantiam argument as one having either of these two forms:

(II) Proposition $A$ is not known to be true; therefore, $\mathrm{A}$ is false.

(12) Proposition $\mathrm{A}$ is not known to be false; therefore, $A$ is true. ${ }^{30}$

By doing this, he identifies ad ignorantiam with a pattern of reasoning rather than with a mistake or fallacy in reasoning. Walton quite rightly points out that although arguments of the form (I1) and (I2) are not in general valid, if a thorough search has failed to produce any appropriate evidence, then we have plausible grounds for accepting the conclusion. (Should we want to define the fallacy of ad ignorantiam, then, we should say that such an argument instantiates (11) or (I2) and gives us no reason to believe such a search has been carried out.) This much is straightforward and quite conventional. I find Walton's discussion flawed, however, when he goes on to discuss certain examples. The problem again is lack of focus. He considers the example

I do not know that this rifle is unloaded.

Therefore, it is reasonable to presume that it is loaded. ${ }^{31}$

Despite Walton's claim, this argument is not an instance of (12). To say "it is reasonable to presume that it is loaded" is not the same as to say "It is loaded." The former does not entail the latter or vice versa. The former is concerned with policy decisions or with the presumptions which should inform policy decisions. The latter makes a factual claim about the rifle. The problem grows with the moral Walton draws from this. He points out that in most contexts it would be reasonable to presume the rifle loaded. But should one be a soldier in battle, the opposite presumption is justified. Hence Walton concludes, "It is the context of dialogue that can make an ad ignorantiam argument plausible or implausible in a given case."'32 This spreads an unfocused haze over the whole discussion. Walton has confused two issues-what presumptions a body of evidence creates for or confers on a claim and what policy presumptions may be reasonable in certain circumstances. Does the fact that I don't know a rifle is unloaded create an epistemic presumption that it is, in the absence of any evidence that a reliable observer has checked the rifle? I think not. However, what policy presumptions one should adopt towards the rifle, especially in light of the fact that we do not 
know it is unloaded, is another matter. Notice that when Walton appeals to context, he does not give us any general principles for deciding when a context makes an ad ignorantiam argument plausible. He leaves this at the intuitive level. How are we to determine whether a given ad ignorantiam argument is fallacious? By confusing issues and appealing to intuitive appraisals of context, Walton leaves the reader at sea here.

There is another problem. I do not see that the concept of dialogue or persuasion dialogue enters in any substantial way into Walton's discussion of ad ignorantiam arguments. Certainly (I1) and (I2) are forms of argumentative texts or forms according to which argumentative texts can be construed or reconstructed, texts which are presented independently of any two-party dialogue. Again, should an argument include the premise that an adequate, significant, or exhaustive search has been done, we still have a monological argument. I do not see how referring to the situational context of the arguer, whether he is at home or in battle, brings in dialogue. Where in all this does dialogue come in?

3. Further considerations on questions. Lack of focus also affects Walton's advice on when to reply to a question with a question. The problem is that rhetorical and logical concerns have gotten mixed together. Walton quite rightly points out that when a questioner poses a question with questionable presuppositions, e.g. a loaded question, he incurs the burden of proof to justify those presuppositions. The best way an interlocutor could respond to such a question is by asking for such justification. But Walton goes on to say

\footnotetext{
When a question is posed aggressively, it often does shift the burden of proof onto the respondent to justify his position. If he fails to do this strongly enough, the accusations in the question may appear to be conceded and confirmed. ${ }^{33}$
}

Perhaps the burden of proof may be shifted in a rhetorical sense, without some justification from the respondent he may appear discredited before the audience. But if the presuppositions of the question are themselves questionable, they remain questionable and should not be admitted or accepted even if the question itself is an effective aggressive tactic. In developing a means for the logical appraisal of argumentation, the rhetorical effectiveness of the move is beside the point.

Walton's mixing and conflating of the rhetorical and logical standards is blatant in the following passage:
Generally, the best strategy for the answerer of such a question is to try to deflect the burden of argument back onto the questioner while trying not to appear too evasive. But then, of course, the best strategy for the ques - tioner is to accuse the answerer of being irrel- evant, or of failing to answer the question. ${ }^{34}$

If the presuppositions of a question are questionable, then certainly, from a logical point of view, they should be questioned and not accepted unless or until justified. Whether questioning them makes one appear evasive is beside the point, logically although not rhetorically. In the first sentence, Walton has given two types of advice. But his advice to the questioner in the second sentence is completely rhetorical.

This conflating of rhetorical and logical concerns is manifest also in Walton's discussion of question-answer rules in dialogue. He asks,

When exactly does a question become objectionable? We have seen that questioning becomes especially dangerous and objectionable when it becomes too aggressive. ${ }^{35}$

But aggressiveness is a rhetorical, not a logical concept. From a logical point of view, a question is not objectionable because it is aggressive, but because it seeks to force accepting unjustified commitments through its unwarranted presuppositions.

4. Irrelevance. Lack of focus is especially acute in the third chapter of Informal Logic, "Criticisms of Irrelevance." Walton begins by presenting the notion of an issue. An issue is a disputed proposition or question. Walton holds that in a dialogue which 
qualifies as a dispute or disputation, one side will seek to maintain that the proposition is true and the other that it is false. These are their contrary theses. "The two theses of the two participants in the argument define the issue of the argument." 36 I ask why must both sides in a dispute be committed to opposing theses for there to be an issue? As long as one side is committed to defending a thesis and the other side to questioning it, we should have an issue. This would be the situation in what Walton calls asymmetrical persuasion dialogues, where only one participant has a thesis to prove and the other raises critical questions. Why cannot some disputes be embodied in asymmetrical persuasion dialogues?

After defining the notion of issue, Walton first considers the traditional ignoratio elenchi fallacy. I find his discussion here both confusing and confused. He considers the example of a senator who, while allegedly arguing for a particular piece of housing legislation directs his whole argument to the conclusion "that all people should have decent housing." "37 Walton then says that from one point of view, the argument could be construed this way:

Premise: All people should have decent housing.

Conclusion: This particular proposal will improve the housing situation. ${ }^{38}$

I would like to know from whose point of view? This seems to represent the senator's conclusion as his premise--quite confusing, at least to the perceived readership of Walton's book. Of course, one could say that the senator intended his conclusion that all people should have decent housing to serve in turn as a premise supporting that the proposal will improve the housing situation-leaving this inference implicit. The point is that Walton does not say that, and without such an explanation it is hard to see how the argument could be construed the way he does.

Walton also seems confused about just what the senator was supposed to show as his main or final conclusion. Was it
This particular proposal will improve the housing situation

or

\section{This bill deserves support?}

I would have thought the latter, with the former perhaps being argued for as an intermediate conclusion. But Walton seems to think it was the former claim. Given that, certain of Walton's further comments seem quite confused. He says

Notice, however, that the senator's argument
could possibly be improved if he could go on
to show why the proposal at issue could pro-
vide decent housing in the present circum-
stances. Then the premise 'All people should
have decent housing' would not be irrele-
vant, because it would be an essential part of
a valid argument for the right conclusion.

Far from making "All people should have decent housing" an essential premise in a valid argument, such argument should make the premise redundant or superfluous, if the conclusion is what Walton alleges! An argument that the proposal provides decent housing would in itself support the claim that this particular proposal will improve the housing situation. It has no need of the additional premise that all people should have decent housing. Of course, we might very well need both claims to infer that the bill deserves support.

These considerations about Walton's confusion blunt the moral he tries to draw from his discussion:

In other words, though the senator's argument... is open to criticism or questioning for what it lacks, it is not necessarily a fallacious argument if by "fallacious" we mean illogical or so hopelessly bad that it cannot be repaired by continuing with it...So although irrelevance should rightly be open to criticism in reasonable dialogue, to call irrelevance a fallacy in every case is an exaggeration. ${ }^{40}$

True, if we can supply a plausible premise which will link the manifestly stated premises of an argument with its apparently irrelevant conclusion in a way which explains their relevance, a charge of ignoratio elenchi is premature. But Walton has not shown that such a charge is premature in this case. 
Walton says something important in this connection which could be more focused if he had availed himself of the process/product distinction. He remarks "The question of how final the criticism of irrelevance should be taken... depends on whether the dialogue can be continued." 41 There is something quite right in this statement, but it needs to be brought into focus. If we are evaluating an argumentative text, an argument as product, then the "dialogue" is finished. If a premise is apparently irrelevant to a conclusion, if there is no suppressed premise the audience could reasonably be expected to supply, then a charge of irrelevant reason fallacy would be warranted. ${ }^{42}$ Even if the arguer could have argued further, he did not. It is not incumbent on us to do his arguing for him. We should judge the product on its own merits. On the other hand, in a developing argument in dialogue, a challenger may very properly ask at certain junctures why a given proposition is relevant. She should not conclude that we have an ignoratio elenchi here until after the proponent has responded. Of course, a proponent's not being able to answer is a significant indication of irrelevant reason. But here the proponent must be allowed to answer. But it would seem that only in the context of an ongoing dialogue do we have the possibility of continuing the dialogue. Walton's talk then of the finality of a criticism of irrelevance would seem to apply to arguments as products.

Subsequent discussion of relevance or the lack of it in Chapter Three is flawed, to my mind, by the fact that Walton operates with a completely intuitive notion of relevance. Now, to be sure, the concept of relevance is intuitive and may be hard to define. As Trudy Govier points out, "The concept of relevance is so basic to thought and the development of knowledge that it is difficult to define and explain." 43 But when a logic text or a handbook for critical argumentation addresses the question of relevance, we would expect some definition or precising characterization of the form. For example, Govier offers "The statement $A$ will be relevant to the statement $\mathrm{B}$ if $\mathrm{A}$ either counts toward establishing $\mathrm{B}$ as true, or counts against establishing $B$ as true. If the truth or falsity of $\mathrm{A}$ has absolutely nothing to do with the truth or falsity of $B$, then $A$ is not relevant to $B .{ }^{, 44} \mathrm{I}$ do not find any such characterization underlying Walton's discussion of various examples. He quotes the mayor of Detroit's claim that a question about the murder rate in Detroit is not relevant to No Crime Day, an appeal to keep Detroit free from crime for a day. Walton rejects this claim, arguing that "murder is clearly related to crime, and to No Crime Day as a topic." 45 But for the purpose of giving the reader some principle or criterion to apply in determining when a question is relevant to a topic, this is surely uninformative. If $\mathrm{A}$ is "related" to $\mathrm{B}$ and $\mathrm{C}$ is "related" to $\mathrm{B}$, does this mean that any question involving $\mathrm{A}$ is relevant to C? Again, in criticizing an argument that the question of tuition fees is relevant to the issue of the library remaining open for longer hours on Sundays, Walton remarks that the connection made in the argument between the two topics is not strong enough to reply to the objection that the topic of fee decreases is not relevant to the issue of library hours. ${ }^{46}$ But Walton has given us no criteria for determining strength of connection. In their absence, we can certainly ask why the connection is not strong enough. The lack of such criteria makes Walton's discussion unfocused. Walton gives some practical advice on aiding judgments of relevance through setting an agenda, but determining relevance to an agenda item is by and large left at the intuitive stage.

Interestingly enough, Walton does present certain characterizations of relevance in the summary section of the chapter on relevance. He distinguishes subject-matter relatedness, "whether the premise is connected to the conclusion by sharing some common subject matters, "47 with probative relevance, "whether the premise plays some role in counting towards or against the con- 
clusion at issue." 48 This is no doubt a valid distinction. But one wonders why a logician should be concerned much with subject matter relatedness, except as a preliminary notion. With the exception of those cases which have bothered relevance logicians, such as a contradiction entailing anything or anything entailing a tautology, subject matter relevance is a necessary condition for probative relevance. It is probative relevance which fails in fallacies of relevance, and it is this concept which needs clarification and development.

5. Argumentum ad populum. Two distinct patterns of argument are standardly classified under the heading of argumentum ad populum. What we might call the grandstanding appeal attempts to persuade the audience of some conclusion by arousing gut emotions in the absence of "hard" evidence. Appeals to popularity argue that because many, more, most, everybody is believing or doing something, you should too-it is right or appropriate. ${ }^{49}$ Walton's characterization of the argumentum ad populum seems to span both versions.

The ad populum (to the people) fallacy is traditionally characterized as the use of appeal to mass enthusiasms or popular sentiments in order to win assent for the conclusion of an argument not supported by good evidence. ${ }^{50}$

I, for one, find this characterization ambiguous. Are these enthusiasms and sentiments mass enthusiasms and sentiments because many people hold them, they are common gut reactions (grandstanding); or are they enthusiasms and sentiments for mass behavior or opinion (popularity)? Walton suggests that he is discussing popularity when he continues, "Most of us like to think that our views are in line with popular trends, and any feeling that we are left out of the accepted styles or leading opinions of the day would not be welcome." si But the rest of the section is devoted to an apparent grandstanding appeal.

Lack of focus is a problem in the discussion of this particular example. Walton begins by telling us he is presenting an ex- ample of a persuasive argument. He describes a television commercial which associates warm, positive images of family life with an insurance company. This is an example of what we might call emotional transfer by association. The emotions associated with some image are transferred to some product, company, or cause. In many cases, it is not at all clear that these messages contain or express arguments, and this is true of the example Walton presents. Furthermore, by the middle of the section Walton concedes that it might not be an argument! Perhaps the insurance company was just trying to draw attention to itself rather than to argue that its insurance products were superior to those of its competitors. Walton claims that we should settle which at the confrontation state of a dialogue, but when are we in dialogue with an advertiser? We may view advertising appeals which proceed by setting up emotional associations as persuasive discourse. As such, they might be reconstructed as arguments. Ordinarily these would be so blatantly fallacious as to be ridiculous. They would certainly be grandstanding appeals, substituting arousing emotions for giving any hard evidence. And, as Walton points out, they would fail as arguments precisely because they substituted largely irrelevant images for pertinent evidence. But they need to be reconstructed or construed as arguments. I think Walton's discussion would be much more focussed if his example were a clearcut argument.

Failure to clearly distinguish grandstand from popularity appeals plagues Walton's discussion of the next example. Focus is missing because there is a switch in the middle of the section from one type of ad populum appeal to the other. Walton begins by discussing an example where the speaker appeals to sentiments of group solidarity and tries to pass himself off as a member of the group-we good farmers must stand together and fight for our rights. This is a classic example of the grandstand appeal. In discussing why such an argument may be fallacious, Walton suggests that 
Instead of advancing objective premises that any reasonable person should accept, [it] uses premises that may be weak but have strong rhetorical appeal to the sentiments of group solidarity of an audience. Surely such a selectively subjective appeal is open to the charge of being fallacious. ${ }^{52}$

But Walton continues by saying that " "popular belief does not establish the truth of a matter. " 53 Instances of the following schemata are at best weak arguments:

(P1) Everybody accepts that $A$ is true. Therefore, $\mathrm{A}$ is true.

(P2) Nobody accepts that $A$ is true. Therefore, $\mathrm{A}$ is false. ${ }^{54}$

The problem is that these schemata are certainly not instanced by

(P3) We-- the members of the audience together with the speaker or some identifiable group of people]-are good, decent, upstanding, wonderful people. Therefore, we must stand up for our rights.

Or

I am one of you good, upstanding, wonderful people.

Therefore, you should support me or what I suggest.

Walton has jumped from discussing one type of argument to another. This is all the more a pity, since he has some very good things to say about (P1) and (P2). Although it is a fallacy to regard such arguments as giving strong or conclusive evidence for their conclusions, in themselves such arguments need not be fallacious. Their premises may make their conclusions plausible or, in the absence of countervailing evidence, may create a presumption for their conclusions. Walton is on solid ground here, for that there is a presumption for the status quo or received view is one of the basic principles of presumption. We may agree with Walton that " $(\mathrm{P} 1)$ and $(\mathrm{P} 2)$ are weak, but sometimes reasonable types of argumentation." 55 The problem is that Walton has not distinguished the two varieties of ad populum argument, but has rather combined or conflated them, putting his discussion out of focus.

6. Deductive validity and argument analysis. At the beginning of Chapter Five, "Valid Arguments," Walton makes a statement which strikes me as surprising. He points out that complex arguments may be compounds of simpler arguments. He then says "Often the best way to get a handle on a large and complex network of argumentation is to identify and clearly state one or more of these subarguments. For this purpose, it is necessary to understand the concept of valid argument." 56 This runs counter to much current informal logic pedagogy, at least as reflected in current informal logic texts. Surely, getting a handle on a complex argument involves seeing how the subarguments hang together. For this, many authors recommend the circle and arrow diagramming technique developed by Monroe C. Beardsley and Stephen N. Thomas. But if we look at the texts of Beardsley, Thomas, Govier, John Eric Nolt, and others, ${ }^{57}$ we find that discussion of argument diagramming precedes discussion of deductive validity. Does Walton know something that all these authors do not? Walton does offer the following justification for his claim: "With this ideal [of a valid argument] in mind, it can be much easier to organize an argument and to interpret it fairly prior to considering evaluation. "'58

Walton speaks directly to this point in the second section of Chapter Five. He acknowledges that should a single argument be presented with a logical indicator, it is straightforward to distinguish premises and conclusion. We need not take questions of validity into consideration. Problems may arise when no logical indicator is present. Walton bids us consider the following:

Air safety should be given high priority. If we must try to prevent disastrous accidents, then air safety should be given a high priority.

We must try to prevent disastrous accidents. ${ }^{59}$

Walton takes it for granted that we do have 
an argument here. (Is that debatable? Could this be plausibly interpreted simply as the assertion of three statements?) Granting that the passage is an argument, we must be able to distinguish premise from conclusion. Taking the first statement as the conclusion and the remaining two as premises seems the most plausible reconstruction. Why? As Walton puts it, "This interpretation is the one that made the resulting argument valid." 60

But I am haunted by the question-Why should the interpretation which makes the argument valid be the best or most plausible interpretation? The second and third statements do entail the first. Now when in a passage statements are juxtaposed with some further statement which they entail, that is a sign that the passage is an argument from the entailing statements as premises to the entailed statement as conclusion. The passage suggests this interpretation because of these factors. If this interpretation is correct, is it correct, the most plausible because it results in a valid argument or because it most correctly or plausibly interprets the suggestions the passage makes? Entailment suggests argument, but it would seem an interpretation is correct because it correctly construes the intentions and suggestions of a passage, not because it construes the passage as expressing correct entailments or valid arguments.

To say that the interpretation is correct because it construes the argument as valid seems out of focus. Whenever we can find statements in a passage which entail some other statement in that passage, is it most plausible to regard that subpassage as an argument? Suppose the statements in the subpassage were scattered throughout the passage? Might that not be to read something into the passage? The point is that entailment may, under some circumstances, suggest argument. Recognizing entailments can heighten our sensitivity to what a passage suggests. Walton is right in saying that recognizing valid arguments may help in analyzing argumentative passages. But it is the fact that a suggestion of argument can be found in a passage which is the mark of why we may plausibly interpret that passage or a subpassage as an argument.

We must raise another critical question at this point. Are entailments the only relations between statements which may suggest arguments? If a set of statements gives evidence for some claim, inductively supporting it without entailing it, and the set is juxtaposed with a claim in a given passage, don't we have a definite suggestion of argument here? What is so important about validity that it should be singled out for exclusive attention here? Interestingly enough, Walton does acknowledge the appropriateness of taking inductive considerations into account at the end of the next section. If his discussion were organized around factors suggesting arguments, he could have integrated that consideration right here.

7. Valid and invalid arguments. Recall that Walton calls this work a handbook, which presumably is an introduction to the subject for the general educated reader. I think it would be quite difficult for someone unfamiliar with basic formal logic to extract a method of evaluation from Walton's discussion of invalid arguments (Chapter Five, Section Five). Walton speaks of the specific form of arguments and of propositional connectives. But I do not believe he has said what propositional connectives are at this point in the essay, ${ }^{61}$ nor has he given us any general method of identifying the specific form of arguments. Those familiar with Copi's discussion of these concepts in [1986], for example, would know how to apply these notions. Walton at best gives us an intuitive characterization.

Again, explaining why

All rodents are mammals.

Some mammals have horns.

Therefore, some rodents have horns.

is invalid, Walton says "the first premise makes a claim about all rodents, but it does not make a claim about all animals." 62 Is this a sufficient explanation for someone not familiar with the classical distinction of 
distributed and undistributed terms? Walton's discussion of why modus ponens is a valid argument form also strikes me as difficult to comprehend for someone without a background in formal logic. He says, "We could interpret the conditional as meaning that it is not true that $A$ is true and $B$ is not true. "63 Would anyone not familiar with the truth-table definition of the material conditional in symbolic logic see why the conditional should be interpreted this way? Walton's discussion of why modus ponens is valid, based on this definition, is certainly cogent, but I expect the general reader would find it quite convoluted. Again, we ask what is the intended audience for this book? Has Walton focused on this?

8. Definition of "semantic." Walton defines a semantic concept as "one that has to do with truth and falsehood." "64 This is just not accurate, given the way "semantic" is standardly understood in the literature. Semantics has to deal with how language, regarded as a syntactic structure, links up with "the world" or "reality." To be sure, if we accept at some level a correspondence view, statements are true because of the way the world is. Truth is a semantic notion. But semantics is much broader, involving issues of meaning beside those of truth.

9. Arguments ad hominem. Walton distinguishes the standard abusive, circumstantial (you-too), and appeal to vested interest (attack on impartiality) varieties of the ad hominem appeal. He makes some very interesting remarks about the circumstantial type. Textbooks standardly regard such arguments, where a critic in effect argues that a proponent's argument should be rejected because that proponent does not practice what he preaches, as fallacious. Yet, there is something unsatisfying in all this. If someone advocating a position or policy does not practice what he preaches, has he not seriously compromised himself as a moral agent? Isn't there something right or apposite, then, in a properly sustained charge of inconsistency?

Walton proposes that the proponent's conclusion may be interpreted in two ways.
On the impersonal interpretation, the proponent is simply saying that a policy is good or advantageous, at least for persons with certain goals. To cite Walton's example, a smoker could argue that smoking is unhealthy, giving substantial reasons as his premises. On the other hand, we could take the conclusion personally as saying "I advocate this policy." But how could a smoker maintain that he advocates a policy of nonsmoking? Walton points out, quite rightly, that the charge that a proponent's conclusion, taken personally, is inconsistent with his practice does not touch the argument to the conclusion taken impersonally. To think that it does is to commit a fallacy. But clearly to show that a person advocates a policy inconsistent with his practice is not, in itself, to argue fallaciously.

This distinction may be illuminating in showing why standard accounts of the circumstantial ad hominem seem lacking. Nonetheless, I have a misgiving here. My question is-What is the purpose of making this point about the personal inconsistency of the proponent? If the point at issue is whether a given policy is good or advantageous, what difference does it make if the proponent engages in behavior inconsistent with his advocating that policy? It may be legitimate to charge an arguer with inconsistency, but what does this show about the argument? It may be a persuasive and so shrewd move on the opponent's part. But how does it advance the dialogue? Isn't the point of the dialogue (or at least this part of it) to come to some rational agreement on the proponent's conclusion interpreted impersonally? Just what is the connection between the personal and impersonal forms of the conclusion?

This problem underlies my misgivings about Walton's claim that there are nonfallacious ad hominem arguments, to which he devotes section four of Chapter Six. Walton considers the example of George who argues that we should allow private, for profit mail delivery companies to compete with the government postal service, because recent postal strikes have destroyed reliable mail service. But George, his 
challenger Bob points out, is a communist. "Bob," Walton claims, "seems to have a reasonable point." 65 I am bothered by the word "reasonable." If George is a dyed-inthe-wool communist, and such communists are inextricably opposed to private enterprise, then the point seems well taken that by advocating free enterprise in this case, George has taken an inconsistent position. Claiming that George is inconsistent is a defensible and so reasonable point. But by making it, is Bob involved in the logical evaluation of George's argument? Is he posing a challenge to it on logical grounds, grounds concerning the justification of George's claim? George is not arguing from an inconsistent premise set. Nor is his conclusion inconsistent with his premises. Why should his argument be rejected, on logical grounds, because its conclusion is inconsistent with other beliefs he holds? When Bob raises the issue of George's being a communist, is he playing the role of challenger to George's argument or is he propounding an argument of his own, with conclusion left implicit that George is being inconsistent here?

Now, to be sure, inconsistency is a central logical concept. To show that a set of statements is logically inconsistent is to do logical analysis and evaluation. In the light of this analysis, George might want either to withdraw his argument or modify his communist commitment. But I do not see Bob evaluating George's argument here. For a really focused understanding of what is going on, this has to be made clear. If George's conclusion, "I think we ought to allow private, for-profit mail-delivery companies to compete on an equal footing with the Post Office" is taken in the personal sense, Bob's rejoinder can be taken as a critical rebuttal. But surely, doesn't George intend his conclusion in the impersonal sense? Again, Walton may be quite correct in saying that where external evidence is lacking, internal evidence concerning an arguer's inconsistency or lack of "impartiality, sincerity, or trustworthiness" 66 may be sufficient to tip the burden of proof against him as a proponent. But this seems to presuppose logical analysis of his argument (or lack of argument), not to be a part of such an analysis. In bringing forward these considerations, are we criticizing an argument, or are we criticizing the conclusion through constructing an argument of our own? I think we are doing the latter. Yet Walton speaks of criticism. "Bob's criticism is a reasonable argument against the person in reply if it shows that this conclusion does not square with George's own political philosophy. That may be a good criticism." 67 What is it a criticism of? To regard it as a criticism of the argument (and Walton does this) is to blur the focus on the issue.

10. Statistical arguments. Walton's characterization of statistical arguments in Chapter Eight strikes me as quite confused. What I believe he means to say or should say is that such arguments seek to establish a statistical conclusion on the basis of a sample, conclusions involving either an explicit statistical quantifier-' $\mathrm{X} \%$ of S are P," or a quasi-statistical quantifier like "most," "many," "few." Walton however characterizes a statistical argument as "an inductive argument in which the degree of probability of the strength of the argument is either given as a specific percentage (number) or in which a nonnumerical statistical term is used." ${ }^{68}$ But it is just downright confused to regard the statistical or quasi-statistical quantifier as making a claim about how strongly the premises support the conclusion. Such a claim would be made by modal expressions, such as "likely," "probably," "presumably." The statistical or quasi-statistical quantifiers, on the other hand, constitute a factor in how strong a conclusion is being asserted. These are two distinct issues.

11. Arguments from analogy. I am bothered by Walton's claim that "many powerful arguments from analogy are plausible arguments rather than inductive arguments, " 69 because I am bothered by Walton's characterization of plausible arguments: "In a plausible argument, if the premises are plausibly true, then the conclusion is as plausibly true as the least 
plausible premise." 70 Given this characterization, we might say that as valid deductive arguments are truth-preserving, plausible arguments are minimal plausibility-value preserving. But notice that whereas deductive arguments need not be valid by definition, Walton has defined plausible arguments as minimal plausibility-value preserving. While deductive arguments need not have true premises to be valid, plausible arguments presuppose plausible premises. (This seems in danger of confusing or conflating premise adequacy and connection adequacy.) And how do we determine whether an argument is minimal plausibility-value determining? One worries that premise adequacy and connection adequacy considerations may have been conflated when Walton argues that two particular argument schemes are schemes of plausible arguments because both premises are plausible propositions. Do plausible premises make plausible as opposed to inductive (or deductive) arguments? All this has to be clarified to bring Walton's discussion into focus.

\section{A concluding word}

Although we have been very critical of Walton in this review, we want to dispel any suggestion that we have not found positive elements in his handbook. Besides those features noted at the outset, we should add that there are instances where Walton adopts a distinctly illuminating terminology. For example, I find Walton's contrast of ap peals to "the internal position or credibility of a particular individual" with appeals "to external or objective knowledge" $"$ to be quite helpful in delimiting the scope of logic as it is coming to be understood in informal logic circles. Traditional formal deductive logic regards question of the truth of premises as outside the scope of logic. Except for logically true or logically false statements, the truth of a statement is an empirical, not a logical concern. Informal logicians, by contrast, urge that premise acceptability be one of the criteria for logically cogent argument. But what does it mean to say that a premise is acceptable? Although there is agreement that the acceptability of a premise is not the same as its truth, what it does mean is a current open question.

I am persuaded that this question should be answered in the framework of dialectic, and that a central factor in determining the acceptability of a premise - or statement in general-is the epistemic status of the sources which vouch for it. For example, when a proponent in a dialogue makes a claim, he vouches for it. Should his claim be a report of what he has presumably experienced directly, his interlocutor has cause to accept his statement, to presume it true until or unless countervailing considerations come to light. But making such determinations as who vouches for a statement and what is his epistemic status in making it is certainly different from determining what independent evidence exists to confirm or refute the proponent's claim. Since the proponent is internal to the dialogue, whereas the evidence needs to be brought in, this is an internal as opposed to external question. By concentrating on such internal questions, I believe it possible to work out an account of premise acceptability. Although this account will treat issues not in the purview of standard logic, its scope will be delimited, specifically to internal concerns. Not any empirical question will automatically become a logical question. ${ }^{72}$

Again, although I criticize Walton for not making plain how dialogue theory is connected to or throws light upon the central issues of (informal) logic evaluation, this does not mean that such connections cannot be established or that they will not be illuminating when set out. Indeed, I am very sympathetic to this approach, and believe it the right one to pursue in developing informal logic. I further believe that the connections I have criticized Walton for not making can be made, and his basic dialogical approach bear fruit.

Perhaps in many of my criticisms, I have nonetheless paid Walton a subtle compliment. For if not expressed overtly as questions, 
these criticisms indicate where questions can and must be raised. We have not said that Walton's approach is totally wrong, but rather thrown the burden of proof back on him to develop it further. This is the way Walton recommends criticizing arguments that are deficient but not irreparably fallacious. We have commended Walton for this approach. In criticizing such arguments, we should try to draw the proponent into further dialogue. Will this dialogue continue?

\section{Notes}

1 Walton, [1989], p. ix.

2 Walton, [1989], p. 1.

3 Walton, [1989], p. 25.

4 Walton, [1989], p. 83.

5 Walton, [1989], p. ix.

6 Trudy Govier gave this agenda an especially memorable formulation in [1985]. I have incorporated it in my text [1988]. It is my (admittedly subjective) impression that a consersus has formed around these issues in the informal logic community.

7 Walton, [1989], p. 3.

8 Walton, [1989], p. 3.

9 Walton, [1989], p. 3.

${ }^{10}$ Walton, [1989], p. 4.

11 Walton, [1989], p. 5.

12 Walton, [1989], p. 9.

13 Walton, [1989], p. 6.

14 Walton, [1989], p. 16, italics in original.

15 Walton, [1989], pp. 17-18.

16 Walton, [1989], p. 18.

17 Walton, [1989], pp. ix-x, italics mine.

18 Walton, [1989], p. $x$, italics mine.

19 Wenzel, [1979], p. 84, italics in original.

20 Wenzel, [1979], pp. 84-85.

${ }^{21}$ In the light of recent discussion of the standards for appraising arguments, we must point out that by "soundness" we here mean something much broader than the truth of premises and the deductive validity of inferences. How premise adequacy and inference or connection adequacy will ultimately be understood is a current subject of research in informal logic. However, when we use "soundness", we intend it in this broader connotation. See Johnson and Blair, [1987], especially pp. 48-55.

22 Wenzel, [1979], p. 84.

23 Wenzel, [1979], p. 84.

24 Walton, [1989], p. 28.
25 Walton, [1989], p. 29.

26 Walton, [1989], p. 31.

27 Walton, [1989], p. 31.

28 Walton, [1989], pp. 36-37.

29 Walton, [1989], p. 40.

30 Walton, [1989], p. 44.

31 Waiton, [1989], p. 46.

32 Walton, [1989], p. 47.

33 Walton, [1989], p. 49.

34 Walton, [1989], p. 50.

35 Walton, [1989], pp. 55-56.

36 Walton, [1989], p. 60.

37 Walton, [1989], p. 61.

38 Walton, [1989], p. 61.

39 Walton, [1989], p. 62.

40 Walton, [1989], p. 62.

41 Walton, [1989], p. 63.

42 Walton in effect makes this point in the second section of Chapter Three.

43 Govier, [1985], p. 101.

44 Govier, [1985], p. 101.

45 Walton, [1989], p. 71.

46 Walton, [1989], p. 72.

47 Walton, [1989], p. 78.

48 Walton, [1989], p. 78.

49 Copi identifies the bandwagon appeal as a subvariety of the argumentum ad populum, grandstanding being the genus. See [1986], pp. 96-98. Johnson and Blair define the fallacy of popularity as the bandwagon appeal. See [1977], pp. 158-63. Fearnside and Holther clearly distinguish bandwagon from grandstanding appeals, classifying them as different fallaciesimpressing by large numbers versus popular passions. See [1959], pp. 92-96. Our experience has also led us to place these two fallacies under different headings. See [1988], pp. 68-71. 
50 Walton, [1989], p. 84.

51 Walton, [1989], p. 84.

52 Walton, [1989], p. 88.

53 Walton, [1989], p. 89

54 Walton, [1989], p. 89.

55 Walton, [1989], p. 90.

56 Walton, [1989], p. 108.

57 See Beardsley, [1975]. Chapter One: Thomas, [1986], Chapters One and Two; Nolt, [1984], Chapters Two and Three, Johnson and Blair, [1977], discuss argument diagramming in Chapter Eight, but do not have a section on deductive validity. Govier, [1985], discusses generic argument evaluation and diagramming before her chapters devoted specifically to deductive logic. I discuss argument diagramming in Chapters Six and Seven of [1988], before discussing evaluation in later chapters.

58 Walton, [1989], p. 108.

59 Walton, [1989], p. 111.

60 Walton, [1989], p. 113.

61 In the summary to the chapter, Walton does list the propositional connectives 'and, 'not,' 'or,' 'if-then,' along with 'all' and 'some.' He indicates that these are logical constants, which he says means "that they can be clearly defined in a fixed or constant way." (p. 131) This is a totally unacceptable definition. Someone presented with this definition could not distinguish between logical constants and such non-logical expressions as individual constants or predicate constants. At least some of these expressions can be clearly defined, and should these definitions be widely accepted, they might very well remain fixed and constant over a wide variety of contexts.

62 Walton, [1989], p. 128.

63 Walton, [1989], p. 110.

64 Walton, [1989], p. 114.

65 Walton, [1989], p. 154, italics mine.

66 Walton, [1989], p. 156.

67 Walton, [1989], p. 157.

68 Walton, [1989], p. 199.

69 Walton, [1989], p. 258.

70 Walton, [1989], p. 15. Walton gives credit to Rescher, [1976], p. 15 for this characterization.

71 Walton, [1989], p. 172.

72 For additional development of these views, see my $[19$

\section{Bibliography}

Beardsley, Monroe C. [1975]. Thinking Straight: Principles of Reasoning for Readers and Writers. Englewood Cliffs, N.J.: Prentice-Hall.

Copi, Irving M. [1986]. Introduction to Logic, Seventh Edition. New York: Macmillan Publishing Company.

Fearnside, W. Ward and Holther, William B. [1959]. Fallacy: The Counterfeit of Argument. Englewood Cliffs, N.J.: Prentice-Hall,

Freeman, James B. [1988]. Thinking Logically: Basic Concepts for Reasoning. Englewood Cliffs, N.J.: Prentice-Hall.

[19__] "A Dialectical Approach to Statement Acceptability." Proceedings of the Second International Conference on Argumentation 1990. Dordrecht-Holland/ProvidenceU.S.A.: Foris Publications.

Govier, Trudy. [1985]. A Practical Study of Argument. Belmont, CA: Wadsworth Publishing Company.

Johnson, Ralph H. and Blair, J. Anthony. [1977]. Logical Self-Defense. Toronto, Canada: McGraw Hill-Ryerson.
[1987]. "Argumentation as Dialectical." Argumentation 1: 41-56.

Nolt, John Eric. [1984]. Informal Logic: Possible Worlds and Imagination. New York: McGrawHill Book Company.

Rescher, Nicholas. [1976]. Plausible Reasoning: An Introduction to the Theory and Practice of Plausibilistic Inference. Assen/Amsterdam: Van Gorcum.

Thomas, Stephen N. [1986]. Practical Reasoning in Natural Language. Englewood Cliffs, N.J.: Prentice-Hall.

Walton, Douglas N. [1989]. Informal Logic: A Handbook for Critical Argumentation. Cambridge: Cambridge University Press.

Wenzel, Joseph, W. [1979]. "Jürgen Habermas and the Dialectical Perspective on Argumentation." Journal of the American Forensic Association 16: 83-94.

JAMES B. FREEMAN

DEPARTMENT OF PHILOSOPHY

HUNTER COLLEGE-CUNY

695 PARK AVE.

NEW YORK, NY 10021 